d'elite-who have joined neither party, rejecting the extreme ideas alike of the ultra worshippers of bleeding and of its enemies. There have always been, and always will be, patricians of this high class in medicine." Elsewhere he sums up, and still in golden words, the actual value of bleeding. "It may be said that, as a rule, the partisans of bleeding overestimate the value of its effects and the necessity for its use ; and that, on the other hand, those who rarely resort to bleeding have an unreasonable dread of its consequences. It is not true that numbers die from bleeding, as some would have us believe; and still less is it true that those who rarely ever bleed lose as many patients as the partisans of bleeding say they do. Daily observation in hospitals shows the fallacy of both these conclusions; and the truth is, that it is not easy to distinguish between bleedings which are useful and necessary, and bleedings which are hurtful and injurious."

[To be continued.]

\section{Clinical lecoros.}

nY

\section{HEN R Y LEE, EsQ., F.R.C.S.,} SURGEON TO ST. GEORGE'S HOSPITAL.

XIII.-Unusuatly Severe and Protracted Case of Syphilitic Disease cured by Calomel Fumigation : With Observations.

Is 1856, Mr. - contracted syphilis in India, and went under a course of mercury. In June of the same year, secondary symptoms made their appearance. These consisted chiefly of copper coloured patches, appearing first on the palms of the hands, subsequently on the arms and legs, and on the body. Numerous excoriations, very tender to the touch, appeared on the scalp. The nails of the toes and fingers became affected, and in two or three instances they fell off. Iodide of potassium and sarsaparilla were the remedies chiefly employed at this time. The eruption gradually disappeared, and the remedies were discontinued. In about a fortnight afterwards, however, all the symptoms appeared again. The same remedies were given, and the symptoms again disappeared. In about a month after he left off these medicines, the eruption appeared for the third time, now accompanied by sores on the tongue and lips. The tongue was also fissured, and presented some warty elevations. This third attack of symptoms did not yield readily to treatment. The eruption, however, gradually subsided and disappeared, while the patient was taking nitric acid; but reappeared a fourth time, soon after that medicine was left off. Various medicines were now tried, including the liquor potassæ.

In June 1857, the circular spots of discoloration were still apparent on the body; and the affection of the nails had reappeared. The tongue and lips were also at this time affected. A great variety of local applications were made to the nails, and also to fissures on the tongue, without benefit. The whole of the soft palate gradually participated in the disease, and, together with the sides of the tongue, were excessively tender. Nocturnal pain in the limbs and in the head now made their appearance; and $\mathbf{M r}$. became generally out of health, and was subject to much dyspepsia, accompanied occasionally by vomiting and colic.

One of the testicles now became enlarged, and resisted all the ordinary modes of treatment. As there appeared no probability of Mr. - 's being restored to health, he was recommended to return to Europe, which he did in October 1857.

Mr. - remained in England, being under treatment the whole time, until August 1859, when he returned to Bombay. He continued tolerably well until June 1860, when he contracted fever. This was followed by the appearance of ulcers on the legs. These ulcers healed under the internal use of iodine; but were followed by others of a much more intractable character. The latter were treated by nitrate of silver, zinc ointment, and iodine internally. The ulcerations ultimately healed; but shortly broke out again, and he was now treated by nitro-muriatic acid internally.

Mr. - now appeared to recover; but after being again attacked with fever, the ulcers again broke out, and extended much farther than before. Mineral acids, iodine, guaiacum, and a variety of other medicines, were now given without any apparent benefit.

Fearing that Mr. -'s stomach would becone impaired if any more medicine were forced upon him, the surgeon under whose care he was recommended him again to proceed to England with all convenient despatch.

Mr. - arrived in England the second time in September 1861, and underwent treatment by it country practitioner for nine months.

In August 1862, I saw Mr. - for the first time. The upper part of the left tibia was much enlarged and extremely tender to the touch. He suffered much from nocturnal pain in the leg and in the head, accompanied by occasional profuse perspiration.

His legs were scarred in every direction with dark brown cicatrices, and there were some remains of the secondary syphilitic eruptions on the skin. He complained particularly of "flushings of heat", and of pains in the limbs, which were, to use his own expression, " excruciating." Feeling his health undermined, and broken in spirit, he contemplated leaving his profession, and had almost made up his mind to do so.

This gentleman commenced the use of the calomel vapour-bath in August 1862, and continued it steadily for nearly three months. He used occasionally other remedies; but the calomel vapour-bath was the only specific treatment that was adopted. From a very short period after commencing his treatment, his improvement was marked. The enlargement of the upper extremity of the tibia disappeared. The pains in the limbs subsided; the flushings of heat and perspirations ceased. He gained flesh; his spirits revived; and at the expiration of eleven months, he left again to join his regiment in India, apparently cured, and having during that period had no fresh symptom of a specific character. I have had the satisfaction of hearing from this patient that he continued in better health than he had enjoyed for years, on the 1st of January last.

'The foregoing is one out of a large number of cases in which the use of the calomel bath has appeared to have been eminently successful, after all other ordinary remedies had failed.

It very frequently happens that patients return from India or China, having suffered from syphilis. and with their constitutions more or less impaired by the influences of a tropical climate. Such patients have often already taken large quantities of mercury internally; and the further use of the medicine in that form is, for many reasons, inadmissible.

When given internally, mercury produces a direct. effect upon the liver, probably in consequence of its absorption into the portal system; and, in patients 
who have previously suffered from liver complaints, any prolonged irritation of this nature may act most prejudicially.

'íhe absorption of mercury through the skin and mucous membrane of the nose, mouth, and throat, affords, in such instances, an admirable mode of producing the specific action of the medicine without communicating any additional irritation to any of the abdominal organs previously affected.

The symptoms of constitutional syphilis are sometimes masked by the coexistence of other diseases in tropical cliniates; and, at other times, they do not there appear to develope themselves as they would in more temperate regions. Some of the most protracted cases of syphilis that have fallen under my notice, have aiforded instances of the secondary forms of the disease appearing when the patients have been suffering from diarrhœa, or from some form of fever, and when they have, consequently, not been subject to any sustained specific treatment. In some of these cases, the character of the eruption ${ }^{*}$ has long remained unrecognised, and the disease has continued to reappear for years in succession, always being attributed to the depressed state of the patient's health.

As soon as the real nature of the affection has been ascertained after a return to England, such patients have not only been relieved of their eruptions by the judicious use of the calomel bath, but have, at the same time, regained their general health.

Such cases as the preceding afford the best practical answer to those who, on the one hand, maintain that syphilis can be cured without mercury; and to those, on the other hand, who believe that syphilis can be satisfactorily treated by mercury administered internally.

\section{Shriginal Communxiations.}

\section{ON 'THE VALUE OF OIL OF MALE-FERN AS A REMEDY FOR TAPE-WORM, AND ON THE MODE OF ADMINISTERING IT : WITH CASES.}

By J. D. Rendue, M.D., Medical Officer of the Government Convict Prison, Brixton, Surrey.

The report of Dr. Fleming, published in the BrItish Medical Journal on January 16th of this year, on the value of the oil of male-fern as a remedy in tapeworm, has induced me to publish the following cases, all of which were successfully treated with this remedy.

The preparation of the patients by abstinence from solid food, and the mode of administering the oil, were somewhat different from that of the cases given in Dr. Fleming's report. I have, however, in every case of tape-worm which I have treated for the last few years, invariably given the remedy in ques tion, in the way I am about to describe; and the result in every instance, has been the rapid expulsion of the worm after a single dose of the drug.

The prisoners confined in the Brixton Prison are women under long sentences-penal servitude for three years and upwards. Cases of tape-worm are not of unfrequent occurrence among these prisoners during the early part of their sentences. The whole of the cases which follow have occurred since last July.
I will first give a short record of each case, and afterwards add the remarks I wish to make thereon.

CASE I. A. J., aged 22, a thin delicate woman, formerly resident in Liverpool, had been treated for tape-worm for many months before her admission to the Brixton Prison. Portions of the worm had been expelled, and the treatment gave temporary relief, but in a few weeks all the unfavourable symptoms returned. In July 1863, I ordered one dose of the oil of male-fern. A worm six yards and a quarter long was passed, since which she has never complained.

CASE II. S. S., aged 26, a strong and stout woman, formerly resident at Wakefield, had suffered from tapeworm for nine or ten years, for which she had been repeatedly under treatment, taking various remedies, including castor-oil and turpentine. Tape-worms, she stated, had frequently been passed after taking the remedies mentioned, but in two or three months there had always been a relapse. In August, after one dose of the oil of male-fern, a worm four yards and a half long was passed, and from that time she has been quite well.

CASE III is particularly important and interesting. A. B., aged 2*, a healthy-looking strong woman, whose former place of residence was Manchester, was brought to the infirmary from her ward on August 27th, 1863, apparently in an epileptic fit. There had been no previous knowledge or suspicion of the existence of tape-worm; but, in an evacuation from the bowels consequent on the action of a black draught, a single joint of a tape-worm was discovered. The cause of the fit was thereby suspected, and the treatment directed for the expulsion of a worm. After a single dose of the oil of male-fern, a worm four yards in length was passed. This patient had suffered from occasional fits since the age of eleven years, but there had not been, as I before stated, any suspicion of the existence of tape-worm. I have repeatedly seen this woman since August, and up to this time (March 8 th), she has been altogether free from the fits she formerly suffered, and her general health has been good. During the first week of October, she thought that one or two joints of a small worm had on one occasion been passed from the bowels; I therefore at that time, subjected her a second time to treatment, and a thin narrow tape-worm, four inches in length, was passed after the usual dose of the malefern.

In every case of tape-worm which I have treated for the last three years, the mode of preparing the patient, the dose of the male-fern, and the way in which it was given, have been the same; all of which I will now briefly describe. The patient is sent to the infirmary, and late in the evening on the day of admis sion, the treatment is commenced by giving an ordinary two-ounce black draught; on the following day all solid food is forbidden, but an almost unlimited supply of beef-tea is allowed; even milk, which is said to be the favourite food of the worm, I purposely forbid. On the evening of this day, half an ounce of castor oil is administered; and early on the following morning, about thirty-four hours after taking the black draught, two fluid drachms of the oil of malefern are given, suspended in two ounces of thin mucilage of acacia. The result without an exception, in every case which I have thus treated, has been the expulsion of a dead worm within two hours after taking the remedy, and in one instance the worm was passed in fifteen minutes.

I have had no difficulty in getting the patients to submit to this mode of treatment, nor have they complained of hunger. In order, lowever, to enable them to bear without much discomfort the prolonged abstinence from solid food, the supply of good beef- 